\title{
Postoperative Curative Effect of Docetaxel and Nedaplatin Combined Chemotherapy in Advanced Gastric Carcinoma
}

\author{
H. TIAN, J. SHANG, Z. JI, RONGRONG ME, D. SU, Y. WANG AND D. KE* \\ First Affiliated Hospital of Jiamusi University, Jiamusi, 154002, China
}

Tian et al.: Effect of Docetaxel and Nedaplatin Combined Chemotherapy in Advanced Gastric Carcinoma

\begin{abstract}
The present study was aimed to analyze the postoperative curative effect of combined chemotherapy with docetaxel and nedaplatin in advanced gastric carcinoma. In this study, 160 patients with advanced gastric carcinoma were enrolled as study subjects. They underwent radical gastrectomy and were randomly divided into the study group and the control group, each containing 80 patients. The control group was treated with oxaliplatin, leucovorin and 5-fluorouracil combined chemotherapy. The study group was treated with docetaxel, nedaplatin combined chemotherapy. There was no significant difference in shortterm treatment efficiency between the two groups. In terms of 1-year survival rate and 3-year survival rate, the study group was better than the control group, $p<0.05$. There was no significant different in rate of adverse reactions between the two groups. The study group showed better quality of life relative to the control group. For treatment of advanced gastric carcinoma, docetaxel-nedaplatin combination could achieve relatively satisfactory long-term efficacy.
\end{abstract}


Gastric carcinoma, a common malignancy, originates from the epithelium of gastric mucosa. The incidence of gastric carcinoma in China ranks the top among all malignant tumors according to a relevant survey data ${ }^{[1,2]}$. In addition, there are obvious regional differences in the incidence of gastric carcinoma, with southern China has higher incidence than that of northwest and eastern coastal areas. Moreover, the incidence shows obvious age characteristics. People over the age of 50 are high incidence group, with more male than female patients ${ }^{[3-5]}$. In recent years, as people's lifestyles continue to change, dietary structures have been adjusted accordingly, plus the increased work pressure and disruption of the surrounding ecological environment, the incidence of gastric carcinoma is on the rise, tending to attack younger generations.

There are many factors causing gastric carcinoma of which Helicobacter pylori infection (fig. 1) is a major one. Currently, the main treatment for locally advanced gastric carcinoma (fig. 2) is surgery. For failure of radical resection of advanced gastric carcinoma studies have shown local recurrence and distant metastasis to be the reasons, making it necessary to improve the treatment regimen. Chemotherapy for advanced gastric carcinoma can improve survival rate. In recent years, more effective and safer anticancer drugs have been introduced into practice. In this study, the postoperative curative effect of a combination of docetaxel and nedaplatin in advanced gastric carcinoma treatment was investigated.

In this investigation, 160 patients who had been treated for advanced gastric carcinoma at the First Affiliated Hospital of Jiamusi University from January 2013 to December 2017 were enrolled, all of whom were treated with combined chemotherapy after surgery. The inclusion and exclusion criteria for patients were, meeting the diagnostic criteria for advanced gastric carcinoma (fig. 3) stipulated in the 8th edition of Surgery ${ }^{[6]}$ and confirmed by X-ray barium meal, fiberoptic gastroscopy as advanced gastric carcinoma; tumor, node and metastasis staging from stage III to IV; with objectively measurable lesions and an estimated survival time of more than $3 \mathrm{mo}$; patients and their relatives had the right to information and signed formal informed consent developed by the institution; no complication of severe liver, kidney, heart and bone marrow dysfunction, no other malignant tumors; no history of chemotherapy nor poor compliance.

The patients were randomly divided into the study group and the control group, each containing 80 patients. In the study group, there were 46 males and 34 females

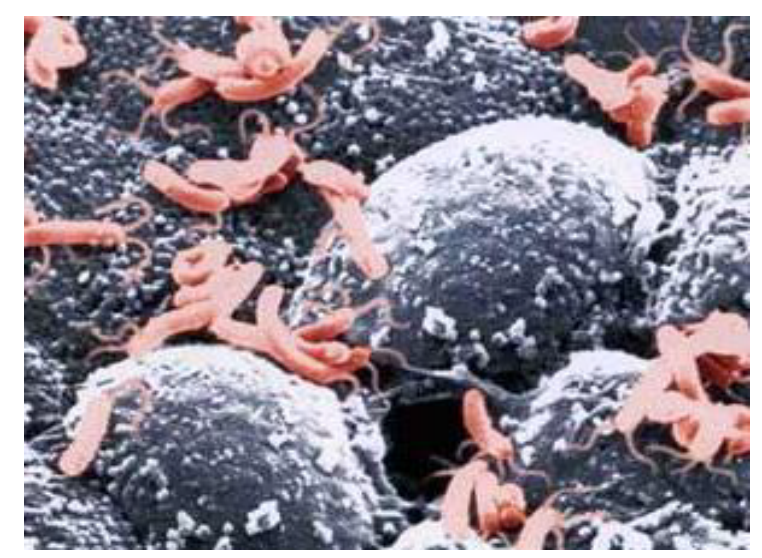

Fig. 1: Helicobacter pylori

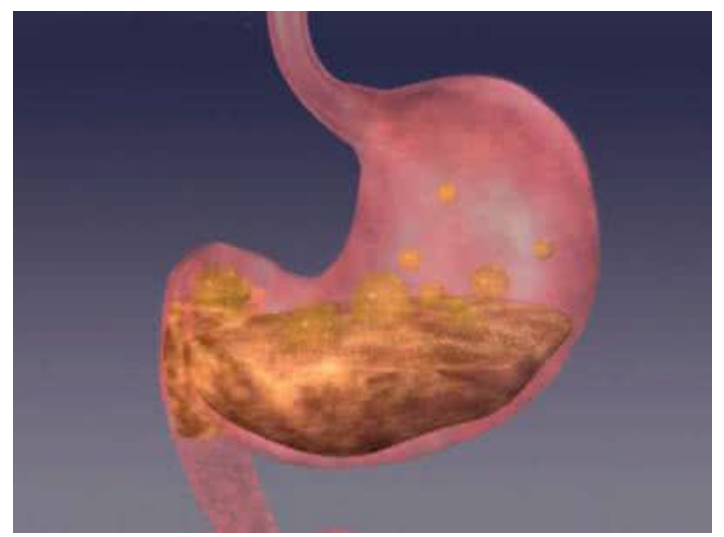

Fig. 2: Advanced gastric carcinoma

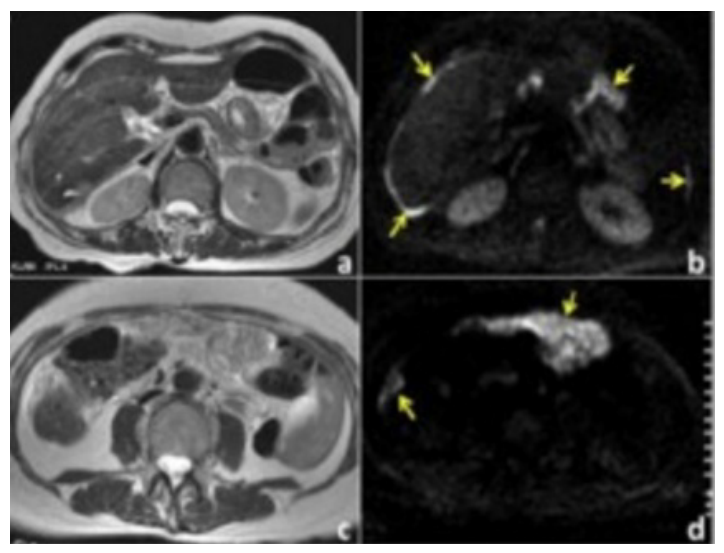

Fig. 3: Imaging of advanced gastric carcinoma 
with age ranging from 40 to $76 \mathrm{y}$, including 30 cases of poorly differentiated adenocarcinoma, 16 cases of undifferentiated carcinoma, 20 cases of mucous gastric carcinoma and 14 cases of signet-ring cell carcinoma. In the control group, there were 50 males and 30 females, with age ranging from 40 to $75 \mathrm{y}$, including 32 cases of poorly differentiated adenocarcinoma, 18 cases of undifferentiated carcinoma, 19 cases of mucous gastric carcinoma, and 11 cases of signet ring cell carcinoma. There is no significant difference in general data between these 2 groups.

The control group was subjected to oxaliplatin, 5-fluorouracil and calcium folinate combined chemotherapy. The main contents include intravenous infusion of oxaliplatin with a specification of $85 \mathrm{mg} / \mathrm{m}^{2}$, infusion time of more than $2 \mathrm{~h}$; infusion of leucovorin, with a specification of $200 \mathrm{mg} / \mathrm{m}^{2}$, followed by intravenous injection of 5-fluorouracil with a specification of $500 \mathrm{mg}$ after $2 \mathrm{~h}$ infusion, and then continuous intravenous drip pump of 5-fluorouracil with a specification of $2.5 \mathrm{~g} / \mathrm{m}^{2}$ for $48 \mathrm{~h}$ infusion. The treatment was conducted once every $14 \mathrm{~d}$, with 2 cycles for a one course of treatment of $28 \mathrm{~d}$. The total courses of treatment was six. The study group was given docetaxel, nedaplatin combined chemotherapy. Intravenous drip of $75 \mathrm{mg} / \mathrm{m}^{2}$ docetaxel and $60 \mathrm{mg} / \mathrm{m}^{2}$ nedaplatin was carried out, once a day, $21 \mathrm{~d}$ for a complete course of treatment. A total of 8 courses of treatment were performed.

The short-term treatment efficacy, long-term treatment efficacy (1-y survival rate, 3-y survival rate) of the 2 groups were recorded and compared. Following the WHO evaluation criteria for solid tumor efficacy ${ }^{[7]}$, the size of gastric carcinoma lesions was evaluated by gastroscopy and barium meal radiography of upper gastrointestinal tract. The status of metastases was assessed using B-mode ultrasonography and computed tomography. Meanwhile, adverse reactions were recorded, which were mainly neurotoxicity, digestive tract reaction, myelosuppression and mucositis. In addition, the physiological scores, psychological scores, social scores, and overall quality of life scores were counted using health status questionnaire, SF-36.

Statistical analysis software SPSS21.0 was used to process data. The measurement data were expressed by mean \pm standard deviation, with $\mathrm{t}$ test conducted for intergroup comparison. Enumeration data were expressed by natural number (n) and percent (\%), with $\mathrm{X}^{2}$ used for intergroup comparison. The intergroup difference is significant when $\mathrm{p}<0.05$.

There was no significant difference in short-term treatment efficacy between the 2 groups. However, the 1-y and 3-y survival rates of the study group were significantly greater than those of the control group, $\mathrm{p}<0.05$, as shown in Table 1 . As shown in Table 2, there was no significant difference in rate of adverse reactions between the two groups. The quality of life scores for the study group were significantly higher as compared to the control group, $\mathrm{p}<0.05$ (Table 3 ).

As a type of malignant tumor, gastric carcinoma

TABLE 1: COMPARISON OF SHORT-TERM AND LONG-TERM TREATMENT EFFICACIES

\begin{tabular}{lcccc}
\hline Group & $\begin{array}{c}\text { Number of } \\
\text { cases }\end{array}$ & $\begin{array}{c}\text { short-term } \\
\text { efficacy }\end{array}$ & $\begin{array}{c}1 \text {-year } \\
\text { survival } \\
\text { rate }\end{array}$ & $\begin{array}{c}\text { 3-year } \\
\text { survival } \\
\text { rate }\end{array}$ \\
\hline $\begin{array}{l}\text { Study } \\
\text { group }\end{array}$ & 80 & $54(67.50)$ & $65(81.25)$ & $60(75.00)$ \\
$\begin{array}{l}\text { Control } \\
\text { group }\end{array}$ & 80 & $39(48.75)$ & $48(60.00)$ & $44(55.00)$ \\
$X^{2}$ & & 9.48 & 10.25 & 12.20 \\
$P$ & & $<0.05$ & $<0.05$ & $<0.05$ \\
\hline
\end{tabular}

TABLE 2: COMPARISON OF ADVERSE REACTIONS

\begin{tabular}{lccccc}
\hline Group & Number of cases & neurotoxicity & gastrointestinal reactions & myelosuppression & mucositis \\
\hline $\begin{array}{l}\text { Study } \\
\text { group }\end{array}$ & 80 & $45(56.25)$ & $20(25.00)$ & $34(42.50)$ & $16(20.00)$ \\
$\begin{array}{l}\text { Control } \\
\text { group }\end{array}$ & 80 & $42(52.50)$ & $22(27.50)$ & $33(41.25)$ & $19(23.75)$ \\
$X^{2}$ & & 0.32 & 0.25 & 0.10 & 0.29 \\
$P$ & & $>0.05$ & $>0.05$ & $>0.05$ & $>0.05$ \\
\hline
\end{tabular}

TABLE 3: COMPARISON OF QUALITY OF LIFE

\begin{tabular}{lccccc}
\hline Group & Number of cases & physiological function & $\begin{array}{c}\text { psychological } \\
\text { function }\end{array}$ & social function & $\begin{array}{c}\text { Overall quality of } \\
\text { life }\end{array}$ \\
\hline Study group & 80 & $0.97 \pm 0.32$ & $1.30 \pm 0.52$ & $1.29 \pm 0.15$ & $4.81 \pm 0.55$ \\
Control group & 80 & $0.43 \pm 0.29$ & $1.01 \pm 0.05$ & $0.82 \pm 0.23$ & $3.26 \pm 1.20$ \\
$\mathrm{t}$ & 3.58 & 5.31 & 5.09 & 8.36 \\
$\mathrm{P}$ & & $<0.05$ & $<0.05$ & $<0.05$ & $<0.05$ \\
\hline
\end{tabular}


incidence is on the raise. Usually, many gastric carcinoma patients have already been in the stage of advanced gastric carcinoma at diagnosis ${ }^{[8]}$. High rates of local recurrence and distant metastasis are still the case after radical gastrectomy for cancer, so attempts to effectively optimize postoperative status of advanced gastric carcinoma has already become an issue of high concern in the medical community. Postoperative chemotherapy is already a standard treatment measure. There are many types of chemotherapeutic drugs with different sensitivity to gastric carcinoma, so patients differ greatly in terms of overall survival ${ }^{[9,10]}$.

Docetaxel is a semi-synthetic taxane analogue with activity more than double that of taxol. With the continuous development of medical technology, docetaxel-based combination chemotherapy regimen has been widely applied in the treatment of advanced gastric carcinoma with remarkable success. Plus its characteristics of higher tolerance, docetaxel was approved by the FDA as the first-line therapy for gastric carcinoma in 2006. Nedaplatin represents a third-generation organoplatinum antitumor drug with solubility 10 times greater than that of cisplatin. Many clinical studies have shown no full cross-resistance between nedaplatin and other platinum drugs. Moreover, nedaplatin can react with nucleosides to produce nucleoside-platinum conjugates that ultimately inhibit replication of tumor DNA.

The results of this study shown similar short-term efficacy of combined docetaxel and nedaplatin chemotherapy and oxaliplatin, 5-fluorouracil, and leucovorin combined chemotherapy. However, the former's long-term efficacy is relatively better with no serious adverse reactions produced and higher quality of life is obtained. Hence, the combination could be used as a postoperative chemotherapy regimen for advanced gastric carcinoma.

In summary, docetaxel and nedaplatin combined chemotherapy could produce good results, with better longer-term efficacy for patients with advanced gastric carcinoma. Moreover, patients can tolerate toxic reactions and receive good quality of life. Therefore, such chemotherapy initiative should be popularized.

\section{REFERENCES}

1. Xu KJ. Therapeutic effect of DOF chemotherapy on advanced gastric carcinoma. Henan Med Res 2018;10(02):283-284.

2. Shen HL, Di CG, Zhu J. The short-term and long-term effects of minimally invasive radical surgery on patients with advanced gastric carcinoma. World Chin J Digestol 2015;23(03):432-7.

3. Endo S, Takiguchi S, Miyazaki Y, Nishikawa K, Imamura $\mathrm{H}$, Takachi $\mathrm{K}$, et al. Efficacy of endoscopic gastroduodenal stenting for gastric outlet obstruction due to unresectable advanced gastric cancer: A prospective multicenter study. J Surg Oncol 2016;109(3):208-212.

4. Rausei S, Dionigi G, Sano T, Sasako M, Biondi A, Morgagni $\mathrm{P}$, et al. Updates on surgical management of advanced gastric cancer: New evidence and trends. Insights from the first international course on upper gastrointestinal surgery - Varese (Italy), December 2, 2011. Ann Surg Oncol 2017;20(12):39427.

5. Misawa K, Mochizuki Y, Ohashi N, Matsui T, Nakayama H, Tsuboi $\mathrm{K}$, et al. A randomized phase III trial exploring the prognostic value of extensive intraoperative peritoneal lavage in addition to standard treatment for resectable advanced gastric cancer: CCOG 1102 study. Jpn J Clin Oncol 2016;44(1):101-3.

6. Cui L, Liu HB, Huang JH, Xu XN. Docetaxel plus nedaplatin combined with concurrent intensity modulated radiotherapy for locally advanced nasopharyngeal carcinoma. J Basic Clin Oncol 2015;28(02):114-7.

7. Li HT, Lei YQ, Xu JF. Observation of postoperative curative effect of combined docetaxel and nedaplatin chemotherapy in advanced gastric carcinoma treatment. Chin J Clin Rational Drug Use 2017;5(21):49-50.

8. Gu HJ, Zhu DM, Ni JY, Xie GD, Mei D, Ni MX. The application value of therapeutic drug monitoring in combined docetaxel and nedaplatin chemotherapy for advanced esophageal cancer. Chin J Cancer Prevent Treatment 2017;24(03):192-5.

9. $\mathrm{Yu} \mathrm{J}, \mathrm{Hu} \mathrm{J}$, Huang $\mathrm{C}$. The impact of age and comorbidity on postoperative complications in patients with advanced gastric carcinoma after laparoscopic D2 gastrectomy: Results from the Chinese laparoscropic gastrointestinal surgery study (CLASS) group. Eur J Surg Oncol 2016;39(10):1144-9.

10. Hamabe A, Omori T, Tanaka K. Comparison of long-term results between laparoscopy-assisted gastrectomy and open gastrectomy with D2 lymph node dissection for advanced gastric cancer. Surg Endosc 2017;26(6):1702-9.

This is an open access article distributed under the terms of the Creative Commons Attribution-NonCommercial-ShareAlike 3.0 License, which allows others to remix, tweak, and build upon the work non-commercially, as long as the author is credited and the new creations are licensed under the identical terms

This article was originally published in a special issue: Special issue on "Drug Development and Human Health in China"

Indian J Pharm Sci 2020:82(1)spl issue2;51-54 